\title{
RESPOSTA PROLIFERATIVA DAS CÉLULAS T CONTRA A CRUZIPAINA NA CARDIOPATIA CHAGÁSICA CRÔNICA
}

\author{
Roberto C. Pedrosa, Edson A Saad, Julio Scharfstein e \\ Alexandre Morrot Lima
}

\begin{abstract}
A natureza dos antigenos do T. cruzi, bem como dos fatores do bospedeiro que contribuem para a cardiopatia chagâsica tem sido intensamente ineestigada nestes últimos anos. Nesse contexto, a caracterização funcional das populações de linfócitos $T$ reativos na fase crônica da doença é particularmente reletante. No presente trabalho, pretende-se analisar a resposta proliferativa de células mononucleares de sangue periférico de pacientes acometidos com a forma cardiaca da doença de chagas. Os estudos se restrigem à cruzipaina, a cisteino-protease majoritária do T. cruzi, uma glicoproteina altamente imunogênica em pacientes chagásicos. Utilizando o indice de estimulação (IE) das culturas de células mononucleares como critério de avaliação de reatividade celular; analisamos 24 individuos: doadores normais $(n=8)$, cardiopatas $n a ̃ a-c h a g a ́ s i c o s ~(n=8)$ e cardiopatas chagásicos crônicos $(n=8)$ sem outras associaçôes mórbidas. Pela análise de variância observou-se que os IE dos pacientes chagásicos são significativamente mais altos do que o valor obseniado nos demais grupos $(p=0,0001)$ enquanto o teste de comparaçôes múltiplas de Tukey revelou que a média do IE dos individuos normais e cardiopatas não-chagásicos não difere significativamente entre si. Nossos estudos indicam que a resposta dos linfócitos $T$, face à cruzipaina, está exclusivamente associada à doença de Chagas. A análise do repertório de epitópos $T$ da cruzipaina e do padrão funcional de reatividade (Th1/Th2) de linfócitos $T$ de sangue periférico está sendo presentemente conduzida. Em vista da abundante expressão de cruzipaina presente en amastigotas, é possĩel que linfócitos $T$ anticruzipaina participen das reações inflamatórias associadas com a cardiopatia chagásica. A caracterizaçâa destas subpopulaçōes poderá oferecer possineis subsídios para a identificação de marcadores de cardiopatia chagásica.
\end{abstract}

Palavras-chaves: Trypanosoma cruzi. Cardiopatia chagásica crônica. Cruzipaina. Doença de Chagas. Linfócito $T$.

A doença de Chagas é endêmica no continente Americano (América do Sul e Central) a tal ponto de que estimativas da Organização Mundial de Saúde apontam que entre 16 a 18 milhões de pessoas estão infectados pelo Trypanosoma cruzi e que mais de 90 milhões estão sob risco de contaminação ${ }^{14} 222428$. Estudos epidemiológicos feitos no Brasil indicam que 8 a 9 milhões de habitantes de zonas endêmicas estão infectados,

\footnotetext{
Serviço de Cardiologia do Hospital Universitário Clementino Fraga Filho da Faculdade de Medicina da Universidade Federal do Rio de Janeiro e Laboratório de Imunologia Molecular $/ \mathrm{ABCCF}^{0}$ da Universidade Federal do Rio de Janeiro, Rio de Janeiro, RJ.

Financiado com verbas da FINEP, CNPq, CFPG e EEC Endereço para correspondência: Dr. Roberto Coury Pedrosa. Centro de Tratamento Intensivo do Hospital Universitário /UFRJ.Av Brig ${ }^{\circ}$ Trompowski s $/ \mathrm{n}, 13^{\circ}$ andar, Ilha do Fundão, 21941-680 Rio de Janeiro, RJ. Fax:(021) 270-8992. Recebido para publicação em 06/11/95.
}

dos quais $20 \%$ apresentam alterações eletrocardiográficas compatíveis com lesões miocárdicas especifícas da cardiopatia chagásica crônica (CCC) ${ }^{47}$. Segundo Dias ${ }^{12}$ mesmo que a doença fosse erradicada hoje, teríamos, por mais de 30 anos, milhares de pacientes necessitando de cuidados médicos, principalmente na forma crônica cardíaca. E esta continua sendo a forma de apresentação da doença de Chagas mais controvertida no que se refere à sua patogenia.

Um número crescente de trabalhos, com utilização de métodos variados de exames, vem reconhecendo a presença de anomalias cardíacas em expressiva percentagem de casos ditos "indeterminados" 112730 . Assim, Lopes e $\mathrm{cols}^{23}$, em um estudo histológico, compararam corações de pacientes chagásicos que faleceram súbitamente com outros falecidos por insuficiência cardiaca congestiva. Concluíram que qualitativamente o processo é semelhante porém, quantitativamente diferentes. Estas 
Pedrosa RC, Saad EA, Scharfstein J, Lima AM. Resposta proliferativa das células T contra a cruzipaina na cardiopatia chagásica crônica. Rerista da Sociedade Brasileira de Medicina Tropical 29:331-339, jul-ago, 1996.

lesões são caracterizadas fundamentalmente por focos de infiltrado inflamatório mononucleares no miocárdio. Carrasco-Guerra e $\operatorname{cols}^{6}$, estudando biópsias endomiocárdicas de pacientes chagásicos crônicos nas diversas formas clínicas, observaram que $60 \%$ dos pacientes sem qualquer evidência de disfunção miocárdica apresentavam alteraçôes à microscopia óptica, eletrônica e histoquímica. Houve maior incidência e gravidade de lesões nos grupos com alterações eletrocardiográficas. Pereira Barreto e cols ${ }^{31}$, mostraram que o infiltrado inflamatório esteve presente em cerca de $65 \%$ das biópsias endomiocárdicas dos pacientes com alteraçōes eletrocardiográficas (com ou sem insuficiência cardiaca congestiva) e em $37 \%$ dos pacientes na forma indeterminada. Higuchi e cols ${ }^{19}$, procurando caracterizar mais detalhadamente o aspecto de atividade da miocardite (linfócitos intimamente acolados ao sarcolema das fibras cardíacas) destes grupos de pacientes chagásicos, constataram que a miocardite em atividade era mais freqüente e mais acentuada no grupo com insuficiência cardíaca congestiva $(92 \%)$, seguindo-se o grupo sem insuficiência cardíaca $(62 \%)$ sendo rara e discreta na forma indeterminada (15\%). Relatos recentes de estudos clínicos reforçam a natureza progressiva da cardiopatia chagásica crônica ${ }^{10}{ }^{29}$.

Todos esses achados fornecem fortes evidências de que a inflamação com agressão às fibras cardíacas tem papel fundamental na evolução da cardiopatia chagásica crônica e na descompensação cardíaca. A evolução clínica da doença seria reflexo de uma contínua progressão da destruição de fibras cardíacas. $\mathrm{O}$ infiltrado inflamatório não representa uma agressão adicional, como admitido no passado, mas sim um elemento essencial para o processo de destruição das fibras miocárdicas através possivelmente do mecanismo de autoimunidade ${ }^{33} 36$ ou reação de hipersensibilidade mediada por células, atuando paralelamente a partir de um estímulo originado pela presença do parasita 3816192036 .

Os mecanismos envolvidos no desenvolvimento das lesões cardíacas contudo ainda não são completamente conhecidos. Entre outras possibilidades, considera-se plausivel que pertubações no sistema imunológico causadas pela interação entre o parasita e o hospedeiro possam promover lesões miocárdicas.

Ao longo dos últimos anos, vários antígenos do Trypanosoma cruzi foram caracterizados.
Entre estes, a cruzipaina (forma nativa purificada da cepa Y epimastigota) ${ }^{3738}$ destacase pela intensidade das reaçôes humorais e celulares ${ }^{32}$ que provoca em pacientes chagásicos. Em estudo recente, a atividade bioquímica e a estrutura parcial deste antígeno foram descritas. A cruzipaina é uma enzima proteolítica, da família das "cisteíno-proteinases", localizada em compartimentos do sistema endossomal-lisossomal e bolsa flagelar do parasita $^{15}$

Como previamente sugerido ${ }^{3520}$, a dupla função independente (atividade proteolítica e imuno-estimulatória) da cruzipaina com seu potencial inflamatório, pode ter participação fundamental na patogenia da doença de Chagas.

Os dados apresentados a seguir sugerem que a reação T linfocitária face à cruzipaina é um componente importante da imunidade celular contra T. cruzi. A análise do repertório de epítopos $\mathrm{T}$ reconhecidos por linfócitos $\mathrm{T}$ anticruzipaina deve ser investigada, como parte de esforços voltados para a identificação de marcadores da cardiopatia chagásica

\section{MATERIAL E MÉTODOS}

Entre Novembro de1990 e Maio de 1995, os pacientes admitidos no ambulatório de Cardiomiopatia do Serviço de Cardiologia do HU-UFRJ com reação de hemaglutinação indireta e imunofluorecência indireta positivas para doença de Chagas, bem como aqueles em que os resultados não foram inequívocos e que tiveram reação positiva para cruzipaina pela técnica de ELISA ${ }^{26}$, foram considerados elegíveis para uma investigação que se propõe estabelecer a utilidade dos diversos métodos de exploração cardiológica no diagnóstico precoce do dano miocárdico. Foram respeitadas as recomendações da $\mathrm{OMS}^{16}$ e da Declaração de Helsinki (1963) revisadas em Veneza (1983). Este estudo foi aprovado pelo comitê local. Foram excluídos pacientes soropositivos para doença de Chagas que apresentassem concomitantemente hipertensão arterial sistêmica, doença pulmonar obstrutiva crônica, miocardiopatia de qualquer outro tipo ou etiologia, doenças orovalvares reumáticas, cardiopatias congênitas e coronariopatia obstrutiva ou portadores de disfunção imunológica. O grupo relacionado foi constituido por 103 pacientes chagásicos, dos quais $25(24,3 \%)$ encontravam-se no grupo II e III da classificação de Los Andes` (Figura 1). 
Pedrosa RC, Saad EA, Scharfstein J, Lima AM. Resposta proliferativa das células T contra a cruzipaina na cardiopatia chagásica crônica. Revista da Sociedade Brasileira de Medicina Tropical 29:331-339, jul-ago, 1996.

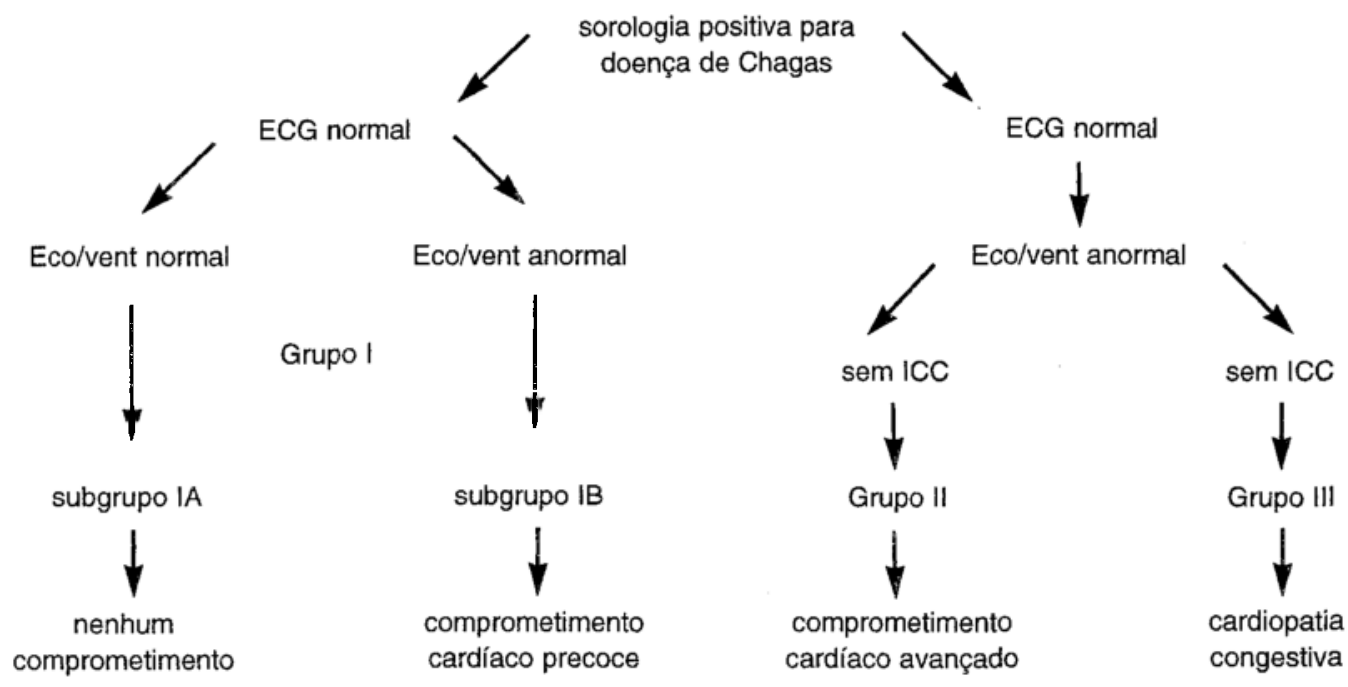

\footnotetext{
Histologia miocárdica:

$\mathrm{IA}=$ celular

$\mathrm{IB}=$ segmentar

II = avançado

III = severo
}

Figura 1 - Classificação clínica-bemodinâmica de Los Andes.

A presente casuística foi composta por 8 indivíduos normais; 8 pacientes cardiopatas não-chagásicos com insuficiência ventricular esquerda e 8 pacientes cardiopatas chagásicos, selecionados de modo aleatório dentre os 25 chagásicos, sendo cinco com insuficiência cardíaca congestiva (grupo III de Los Andes) e três sem manifestação clínica de insuficiência cardíaca (grupo II de Los Andes). A idade, peso, altura e sexo dos indivíduos normais foram similares aos pacientes dos grupos de cardiopatas não-chagásicos e cardiopatas chagásicos $(\mathrm{p}=0,87$; Tabela 1$)$. Os pacientes se encontravam ambulatorialmente em condição clínica estável e todos recebiam tratamento medicamentoso otimizado (digital/diurético/captopril) para prevenir o desenvolvimento de edema periférico e manter o peso corporal $( \pm 1 \mathrm{~kg}$ enquanto em acompanhamento), débito urinário $\geq 1500 \mathrm{ml} / \mathrm{dia}$ e concentração plasmática de eletrólitos dentro da variação normal. Os medicamentos foram suspensos 48 horas precedendo qualquer exame. Nenhuma complicação ocorreu como resultado do estudo.
Todos os pacientes foram submetidos a:

1) avaliação clínica: Para os pacientes chagásicos foi usada a classificação clínicahemodinâmica de Los Andes ${ }^{5}$ (Figura 1). O critério de insuficiência cardiaca congestiva aplicado foi baseado naquele usado no "Framingham Heart Study"25 Como parte do estudo basal de cada paciente foram realizados os seguintes exames: hemograma completo; urinálise; exame de fezes; determinação de glicemia, creatinina e colesterol sérico;

2) avaliação radiológica ${ }^{2141}$, eletrocardiografia de repouso e dinâmica (Holter) assim como ecocardiografia bidimensional com doppler intracavitário ${ }^{+2}$

3) ensaio da resposta $T$ linfócitária: células mononucleares de sangue periférico dos cardiopatas e dos individuos normais foram isoladas através de centrifugação por densidade em Ficoll-Hipaque. Após o isolamento, as células foram congeladas e mantidas em nitrogênio líquido. Para os ensaios de proliferação, as células foram 
Pedrosa RC, Saad EA, Scbarfstein J, Lima AM. Resposta proliferativa das células T contra a cruzipaina na cardiopatia chagásica crônica. Revista da Sociedade Brasileira de Medicina Tropical 29:331-339, jul-ago, 1996.

cultivadas em meio RPMI-1640 (Gibco) suplementado por gentamicina, ß-mercaptoetanol, L-glutamina e 10\% de um pool de soro humano $\mathrm{AB}$ testado previamente para toxicidade e mitogenicidade. $2 \times 10^{5}$ células/orifício foram cultivadas em placas de 96 orifícios de fundo plano por 5 dias na presença do antígeno ou somente com meio. As culturas foram pulsadas com $\left[{ }^{3} \mathrm{H}\right]$ timidina nas últimas 18 horas de cultura. A $\left[{ }^{3} \mathrm{H}\right]$ timidina incorporada ao DNA das células proliferantes foi medida por cintilação líquida e representada como $\mathrm{cpm} \times 10^{3} \pm \mathrm{SD}(\mathrm{cpm}=$ contagem por minuto). O IE foi obtido pela razão cpm da amostra estimulada por cruzipaina/cpm do meio de cultura. Os ensaios proliferativos de cada paciente foram testados pelo menos 3 vezes assim como dos indivíduos normais. A concentração de cruzipaina foi de $2 \mu \mathrm{g} / \mathrm{ml}$, dose esta, estabelecida em trabalho anterior ${ }^{2}$ através da realização de curvas dose resposta.

\section{RESULTADOS}

Caracteristicas clinicas. As principais características clínicas e exames complementares dos indivíduos normais e dos pacientes com cardiopatia chagásica e não-chagásica encontram-se na Tabela 1 . O tratamento medicamentoso não foi significativamente diferente entre os grupos de cardiopatas.

Resposta proliferativa. Os resultados da Figura 2 e Tabela 2 mostram uma grande variabilidade na intensidade de resposta específica à forma nativa da cruzipaina no grupo de pacientes cardiopatas chagásicos, avaliada pelo IE apresentado por estas culturas (média de 4,28 $\pm 2,25$; AIQ de 3,75 e $\mathrm{CV}$ de $52.57 \%$ ). O mesmo não aconteceu no grupo de indivíduos normais (média de 1,21 \pm 0,22 ; AIQ de 0,30 e CV de $18,68 \%$ ) e no grupo de cardiopatas não-chagásicos (média de 1,24 $\pm 0,23$; AIQ de 0,29 e $\mathrm{CV}$ de $18,66 \%$ ). Onde AIQ representa a medida de variabilidade e $C V$ o coeficiente de variabilidade.

Pela análise de variância, observou-se que os IE dos pacientes chagásicos são significativamente mais altos do que o valor observado nos demais grupos $(\mathrm{p}=0,0001)$, enquanto o teste de comparações múltiplas de Tukey revelou que a média do IE dos indivíduos normais e cardiopatas não-chagásicos

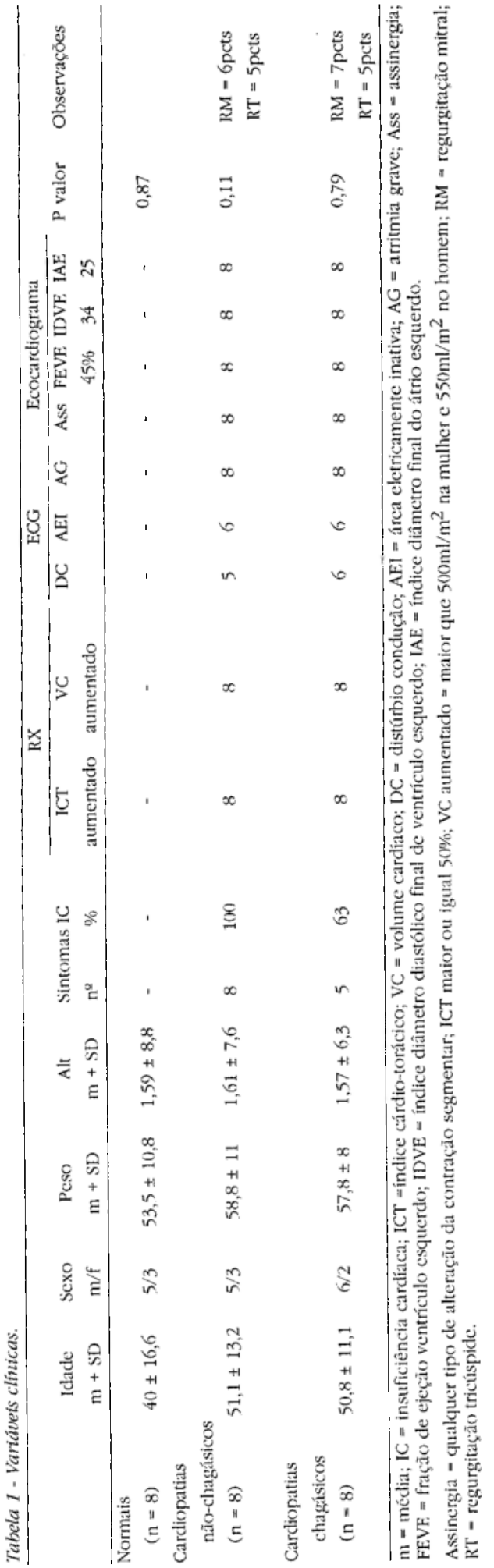


Pedrosa RC, Saad EA, Scharfstein J, Lima AM. Resposta proliferativa das células T contra a cruzipaina na cardiopatia chagásica crônica. Revista da Sociedade Brasileira de Medicina Tropical 29:331-339, jul-ago, 1996.

não difere significativamente entre si (Tabela 2 e Figura 2).

\begin{tabular}{lcccc}
\multicolumn{5}{l}{ Tabela 2 - Análise estatistica do indice de estimulação. } \\
\hline Grupo & $\mathrm{N}$ & Média & DP & p-valor \\
\hline Normais & 8 & 1.21 & 0.22 & \\
Nāo chagásicos & 8 & 1.24 & 0.23 & $0.0001^{*}$ \\
Chagásicos & 8 & 4.28 & 2.25 & $*^{*}$ \\
\hline
\end{tabular}

* Resultado da ANOVA.

** Significativo ao nível de 5\%.

Análise estatística. Os dados obtidos foram submetidos a análise de variância "one-way" (ANOVA) para justificar se existe diferença significativa no IE entre os três grupos (indivíduos normais/cardiopatas nãochagásicos/cardiopatas chagásicos). O teste de Tukey foi aplicado para determinar quais os grupos que diferem entre si. O critério de determinação de significância foi o nível de $5 \%$. O software usado foi o Systat.

\section{DISCUSSÃO}

Existem controvérsias a respeito da patogênese da cardiopatia chagásica ${ }^{17} 2736$. Tem sido demonstrado, tanto na doença humana quanto em modelos experimentais, que durante a fase aguda ocorrem lesões inflamatórias focais, necrose dos miócitos e ninhos de amastigotas no coração ${ }^{1}$. Estas observaçôes sugerem que a patogênese das lesões cardíacas na forma aguda, pelo menos na sua fase inicial, está relacionada à presença de parasitas intracelulares ${ }^{40}$ e a evolução deve, muito provavelmente, estar relacionada a virulência da cepa e à eficácia protetora do sistema imunológico do indivíduo infectado.

$O$ assunto mais controverso reside na patogênese das lesões tardias da fase crônica, quando os parasitas são escassos. Na busca de um maior entendimento sobre este processo, muitos pesquisadores têm sido levados a analisar componentes parasitários e do hospedeiro possívelmente implicados nestas

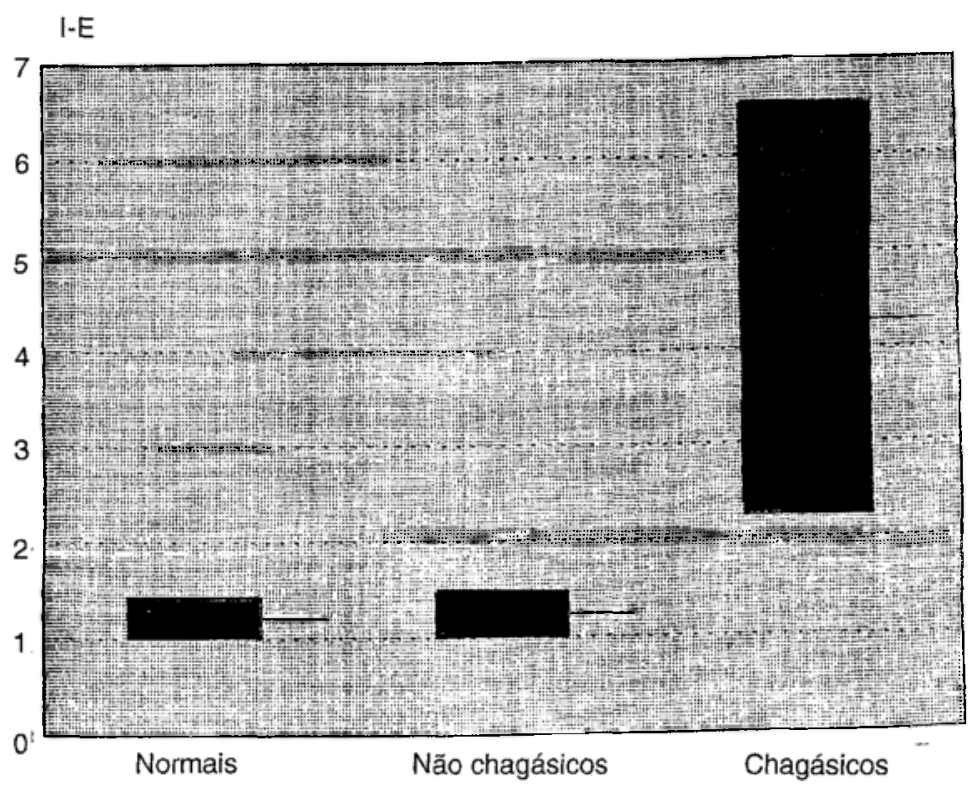

Figura 2 - Distribuição do índice de estimulação da resposta T linfocitária nos diferentes grupos. 
Pedrosa RC, Saad EA, Scharfstein J, Lima AM. Resposta proliferativa das células T contra a cruzipaina na cardiopatia chagásica crônica. Revista da Sociedade Brasileira de Medicina Tropical 29:331-339, jul-ago, 1996.

reações. Vários aspectos têm sido abordados, sendo dada últimamente maior ênfase na caracterização das subpopulações de células T e dos antígenos por estes reconhecidos ${ }^{20} 33$, além das hipóteses que preconizam a participação de mecanismos auto-imunitários.

Uma das hipóteses postula a participação de mecanismos imunológicos, diretamente estimulados por antígenos parasitários, ocasionalmente liberados nos tecidos. Baixas concentrações de antígenos parasitários podem ser suficientes para recrutar infiltrados mononucleares para o local das lesões primárias, ampliando o processo inflamatório 2 . Recentemente, Higuchi e $\mathrm{cols}^{18}$, em material de autópsia, utilizando anti-soro policlonal contra antígenos do $T$. cruzi, demonstraram nítida associação entre a presença de antígeno do $T$. cruzi e inflamação moderada ou acentuada no miocárdio. Estudando as subpopulações de linfócitos, que infiltram o miocárdio em biópsias endomiocárdicas de pacientes com miocardite crônica chagásica, Higuchi e cols ${ }^{20}$ verificaram que as células T formavam $95 \%$ do infiltrado e que as células CD4+ (linfócitos T auxiliares) estavam em menor proporção do que as células CD8+ (citotóxicas), e apresentavam diminuída expressão de suas moléculas de superfície. Dado semelhante foi encontrado por Reis e cols em material de autópsia ${ }^{33}$. Esses autores, também, verificaram que havia um reduzido número de linfócitos, expressando receptor para IL-2. A quantidade de IL-2 sintetizada pelas células CD4t é um fator importante na determinação da magnitude da resposta imune. Assim, os autores sugeriram existir um desequilíbrio imunológico em pacientes com a forma crônica cardíaca da doença de Chagas para o qual, possivelmente, - T. cruzi teria papel fundamental. Está demonstrado experimentalmente que o $T$. cruzi tem a capacidade de diminuir a expressão das moléculas de superfície dos linfócitos, induzindo a imunodepressão no hospedeiro ${ }^{333439}$. A falta de um dos dois subgrupos $(\mathrm{CD} 4+/ \mathrm{CD} 8+)$ leva à diminuição da inflamação e, portanto, da agressão inespecífica a fibras cardíacas não parasitadas, mas acarreta um aumento do parasitismo intracelular e maior mortalidade.

O presente estudo demonstra que a cruzipaina na forma nativa é capaz de estimular células mononucleares de sangue periférico de pacientes chagásicos crônicos com comprometimento cardíaco avançado (grupos II e III de Los Andes). As respostas proliferativas apresentaram intensidade variável (CV de 52,57\%). Além dos fatores relacionados com o polimorfismo de MHC (complexo principal de histocompatibilidade) classe $\mathrm{II}^{32}$, esta variabilidade pode ser reflexo do comprometimento miocárdio variável entre os grupos II e III, definido por métodos histoquímicos e microscopia eletrônica", fazendo supor que a miocardite evolui por surtos durante o decorrer da vida do paciente, sendo mais freqüente e mais grave, na fase que culmina com a descompensação cardíaca. E razoável admitir que tal resultado possa ter conseqüências patológicas, visto que a ativaçâo de células $T$ (linfócitos) de fenótipo $\mathrm{CD}+\mathrm{e}$ perfil Th1 de citocinas (subgrupo de célula $T$ auxiliares) pela cruzipaina resulta na secreção de Gama-Interferon ${ }^{2}$. Em tese, a liberação de pequenas quantidades desta glicoproteína (cruzipaina) poderia amplificar respostas inflamatórias iniciadas a partir de lesões extremamente discretas, recrutando infiltrados mononucleares para o local das lesōes.

As evidências que implicam disfunção imunológica na patogênese da doença de Chagas permanecem circunstanciais. As investigações sobre o repertório de epítopos $\mathrm{T}$ de cruzipaina reconhecidos por pacienies com diferentes níveis de comprometimento cardíaco se inserem nesse contexto, e deverão contribuir para uma melhor compreensão dos mecanismos imunológicos envolvidos na doença de Chagas. A análise do repertório de epítopos $T$ da cruzipaina, e do padrão funcional da reatividade linfocitária (Th1/Th2) envolvido nesta resposta é objeto de estudos em andamento. Abordagem deste tipo poderá eventualmente conduzir à identificação de marcadores de cardiopatia chagásica .

Concluímos que a forma nativa da cruzipaina foi capaz de estimular células mononucleares do sangue periférico de pacientes cardiopatas chagásicos crônicos, obtendo-se respostas proliferativas de intensidade variável. A resposta dos linfócitos $T$ face à cruzipaina está exclusivamente associada com a doença de Chagas

\section{SUMMARY}

In this paper, we sought to determine if chronic chagasic patients with cardiopathy could be 
Pedrosa RC, Saad EA, Scharfstein J, Lima AMT Resposta proliferativa das células T contra a cruzipaina na cardiopatia chagásica crônica. Revista da Sociedade Brasileira de Medicina Tropical 29:331-339, jul-ago, 1996.

distinguished from those displaying non-chagasic cardiopathy on the basis of $T$ cell proliferative responses to cruzipain (GP57/51), a major antigen of T. cruzi. Assays were performed witb peripheral blood mononuclear cells from 24 individuals classified as follows: normal donors $(n=8)$, patients with non-chagasic cardiopatby $(n=8)$ and patients with chronic chagasic cardiopatby without morbid associations $(n=8)$. The analysis of variance indicated that the proliferative responses stimulated by cruzipain were significantly bigher in the group of chagasic patients $(p=0,0001)$. Tukey's multiple comparison test showed that the proliferative index medium from normal and non-chagasic cardiopatby was not significantly different from each other. We conclude that the $T$ cell responses agains $T$. cruzipain, as measured by proliferative indices of cells found in peripheral blood, are exclusively associated with Chagas, disease. In view of the abundance of cruzipain antigen in amastigotes it is possible that these T cell specificities contribute to the heart tissue damage observed in chronic Chagas, disease patients

Key-words: Trypanosoma cruzi. Cbronic chagasic cardiopathy. Cruzipain. Chagas disease. T cells

\section{AGRADECIMENTOS}

Os autores agradecem a Paulo R. da Costa, Cristina Borges e Sá pelos serviços técnicos prestados e a Rosangela Aparecida Martins Noé pela colaboração na análise estatística.

\section{REFERÊNCLAS BIBLIOGRÁFICAS}

1. Andrade $Z A$, Andrade SG. Patologia da doença de Chagas. In: Brener Z, Andrade Z (eds) Trypanosoma cruzi e Doença de Chagas. Editora Guanabara Koogan, Rio de Janeiro, p.148-199, 1979.

2. Arnholdt ACV, Piuvezam MR, Russo DM, Lima APC, Pedrosa RC, Reed SG, Scharfstein J. Analysis and partial epitope mapping of human $\mathrm{T}$ cell responses to Trypanosoma cruzi cysteinyl proteinase.The Journal of Immunology 151:31713179, 1993.

3. Arnholdt ACV, Scharfstein J. Immunogenicity of Trypanosoma cruzi cysteine proteinase Research Immunology 142:146, 1991.

4. Camargo ME, Silva GR, Castilho EA, Silveira AC. Inquérito sorológico da prevalência de infecção chagásica no Brasil. 1975-1980. Revista do Instituto de Medicina Tropical de São Paulo 26:192-204, 1984.
5. Carrasco Guerra HA. Diagnostico de dano miocardico en la Enfermedad de Chagas. Textos de la Universidad de Los Andes. Consejo de Publicaciones de la Universidad de Los Andes, Mérida, 1983.

6. Carrasco Guerra HA, Palácios-Prü E, Scorza CD, Molina C, Inglessis G, Mendoza RV. Clinical, histochemical and ultrastructural correlation in septal endomyocardial biopsies from chronic chagasic patients: Detection of early myocardial damage. American Heart Journal 113:716-24, 1987.

7. Castro-Filho J, Silveira AC. Distribuição da doença de Chagas no Brasil. Revista Brasileira de Malariologia e Doenças Tropicais 31:85-98, 1979.

8. Cunha-Neto E. Imunopatogênese da cardiopatia chagásica crônica humana. Estudo dos linfócitos infiltrantes da lesão e da reação cruzada miosina cardíaca-Trypanosoma cruzi. Tese de doutorado Universidade de São Paulo, 1994.

9. Decourt LV, Sosa EA, Mady C. Forma indeterminada: conceito e aspecto fisiopatológicos. In: Cançado JR, Chuster M (eds) Cardiopatia Chagásica. Fundação Carlos Chagas, Belo Horizonte, p.121-127, 1985.

10. Dias JCP. História natural. In: Cançado JR, Chuster M (eds) Cardiopatia chagásica. Fundação Carlos Chagas, Belo Horizonte, p. 99-113, 1985.

11. Dias JCP. The indeterminate form of human chronic Chagas disease. A clinical epidemiological review. Revista da Sociedade Brasileira de Medicina Tropical 22:147-156, 1989.

12. Dias JCP. A doença de Chagas e seu controle na América Latina. Uma análise de possibilidades. Caderno Saúde Pública. Rio de Janeiro 9:201-209, 1993.

13. Espinosa RA, Carrasco Guerra HA, Belandria $F$, Fuenmayor AM, Molina C, Gonzalez R, Martinez $O$. Life expectancy analysis in patients with Chagas disease: prognosis after one decade (1973-1983). International Journal of Cardiology 8:45-56, 1985

14. Foreign-born population by place of birthselected characteristics: 1980. In: Bureau of the Census - Statiscal abstract of the United States, $110^{\text {th }}$ edition. Government Printing Office, Washington DC, p.41, 1990.

15. Gazzinelli RT, Leme VMC, Romeu Cançaao J, Gazzinelli G, Scharfstein J. Identification and partial characterization of Trypanosoma cruzi antigens recognized by $\mathrm{T}$ cells and immune sera 
Pedrosa RC, Saad EA, Scharfstein J, Lima AM. Resposta proliferativa das células T contra a cruzipaina na cardiopatia cbagásica crônica. Revista da Sociedade Brasileira de Medicina Tropical 29:331-339, jul-ago, 1996.

from patients with chagas disease. Infection and Immunology 58:1437, 1990.

16. Gutterdge F. Human experimentation and medical ethics. International guidelines for biomedical research involving human subjects. WHO chron 35:212, 1981.

17. Higuchi ML. O parasita e a patogenia da forma crônica da Doença de Chagas. Arquivo Brasileiro de Cardiologia 64:251-254, 1995.

18. Higuchi ML, De Brito T, Reis MM, Barbosa A, Bellotti G, Pereira Barretto AC, Pileggi F. Correlation between T. cruzi - Parasitism and myocardial inflammatory infiltrate in human chronic chagasic myocarditis: light microscopy and immunohistochimical findings. Cardiovascular Pathology 2:101-106, 1993.

19. Higuchi ML, DeMorais CF, Pereira Barretto AC, Mady C, Lopes EA, Bellotti G, Pileggi F. The role of active myocarditis in the development of heart failure in chrinic chagas disease: a study based on endomyocardial biopsies. Clinical Cardiology 10:665-70, 1987.

20. Higuchi ML, Gutierry PS, Aiello VD, Palomino S, Bocchi E, Kalil J, Bellotti G, Pileggi $F$. Immunohistochemical characterization of infiltrating cells in human chronic chagasic myocarditis: comparison with myocardial rejection process. Virchows Archiv a Pathological Anatomy and Histopathology 423:157-160, 1993.

21. Keats TE, Enge JP. Cardiac mensuration by the cardiac volume method. Radiology 85:850-855, 1965.

22.Kirchoff LV, Gam AA, Neva FA. American trypanosomiases (Chagas disease) in Central American immigrats. American Journal Medicine 82:915, 1987.

23. Lopes ER, Chapadeiro E, Almeida HO, Rocha A. Contribuição ao estudo da anatomia patológica dos corações de chagásicos falecidos subitamente. Revista da Sociedade Brasileira de Medicina Tropical 6:269-282, 1975.

24. Marsden PD. Selective primary health care: strategies for control of disease in the developing world. XVI Chagas disease. Reviews of Infections Diseases 6:855-865, 1984.

25. McKee PA, Castelli WP, McNamara PM, Kannel WB. The natural history of congestive heart failure. New England Journal of Medicine 285:1441-1446, 1971.

26. Meirelles MNL, Juliano L, Carmona E, Costa EM, Silva SG, Lima ATCV, Arnholdt ACV, Guimaraes
ESP, Berre OJ, Scharfstein J. Functional and antigenic properties of the major cysteine proteinase (GP57/51) of Trypanosoma cruzi. Memórias do Instituto Oswaldo Cruz 85:4, 1990.

27. Morris SA, Tanowitz HB, Witter M, Bilezikian JP. Pathophysiological insigths into the cardiomyopathy of Chagas disease. Circulation 83:1900-1909, 1990.

28. Pan American Health Organization. Health condictions in the Americas. 1990 edition: vol 1. Washington DC. Pan American Health Organization, 1990: annex p.160-164. Scientific publication 524 .

29.Pedrosa RC. Estudo longitudinal do eletrocardiograma na doença de Chagas desde a fase aguda. Tese de Mestrado, Universidade Federal do Rio de Janeiro, Rio de Janeiro p.113, 1987.

30. Pereira Barretto AC, Ianni MB. A forma indeterminada da moléstia de Chagas: conceito e implicações médico-legais. Revista da Sociedade de Cardiologia Estado de São Paulo 4:129-132, 1994.

31. Pereira Barretto AC, Mady C, Arteaga-Fernandez E, Stolf N, Lopes EA, Higuchi ML, Bellotti G, Pileggi F. Right ventricular endomyocardial biopsy in chronic Chagas disease. American Heart Journal 111:397-12, 1986.

32.Reed SG, Pihl DL, Grabstein KH. Immune deficiency in chronic Trypanosoma cruzi infection: recombinat interleukin-1 restores Th function for antibody production. The journal of Immunology 142:2067-2071, 1989.

33. Reis DD, Jones E, Tostes S, Lopes ER, Gazzinelli G, Colley DG, MacCurley T. Characterization of inflammatory infiltrates in chronic chagasic myocardial lesions: presence of tumor necrosis factor + cells and dominance of granzyme A + CD8+ 1ymphocytes. The American Journal Tropical Medicine Hygiene 48:637-644, 1993.

34.Reis MM, Higuchi ML, Aiello VD. In situ expression of cytokines in human chronic chagasic myocarditis. An immunohistochemical study. Memórias do Instituto Oswaldo Cruz 89 (suppl D):129, 1994.

35. Ribeiro dos Santos R, Pirmez C, Savino W. Role of autoreactive immunological mechanisms in chagasic carditis. Research Immunology 142:134, 1991.

36. Rossi MA, Mengel JO. Patogênese da miocardite chagásica crônica: o papel de fatores autoimunes 
Pedrosa RC, Saad EA, Scharfstein J, Lima AM. Resposta proliferatina das células T contra a cruzipaina na cardiopatia chagásica crônica. Revista da Sociedade Brasileira de Medicina Tropical 29:331-339. jul-ago. 1996.

e microvasculares . Revista do Instituto Medicina Tropical de São Paulo 34:593- 599, 1992.

37. Scharfstein J, Rodrigues MM, Alves CA, De Souza W, Previato JO, Mendonca-Previato L. Trypanosoma cruzi: description of a highly purified surface antien defined by human antibodies. The Journal of Immunology 131:972, 1983.

38. Scharfstein J, Schechter M, Senna M, Peralta JM, Mendonça-Previato L, Miles MA. Trypanosoma cruzi: characterization and isolation of a $57 / 51.000 \mathrm{~m} . \mathrm{w}$ surface glycoprotein expressed by bloodstream trypomastigotes. The Journal of Immunology 137:1336, 1986

39. Sztein M, Washington RC, Kierszeubaum F. Trypanosoma cruzi inhibits the expression of
CD3, CD4,CD8 and IL-2R by mitogen-activated helper and cytotoxic-human lymphocytes. The Journal of Immunology 144:3558-62, 1990 .

40. Tafuri WL. Patogênese. In: Cançado JR, Chuster M (eds) Cardiopatia chagásica Fundação Carlos Chagas, Belo Horizonte p.1-10, 1985.

41. Tarasontch F, Vianna CB, Monteiro BLF, Danar D, Grinberg M, Pereira Barreto AC. Valor do Indice Cardiotorácico na avaliação do comportamento cardiaco em miocardiopatias dilatadas. Arquivo Brasileiro de Cardiologia 45:403-406, 1985.

42. Turano MMD. Análise de avaliação funcional da cardiopatia chagásica attavés da ecocardiografia. Tese de Mestrado. Universidade Federal do Rio de Janeiro, Rio de Janeiro, RJ, 1992. 